\title{
LIS research across 50 years: content analysis of journal articles
}

\author{
Kalervo Järvelin and Pertti Vakkari \\ Faculty of Information Technology and Communication Sciences, \\ Tampere University, Tampere, Finland
}

\begin{abstract}
Purpose - This paper analyses the research in Library and Information Science (LIS) and reports on (1) the status of LIS research in 2015 and (2) on the evolution of LIS research longitudinally from 1965 to 2015.

Design/methodology/approach - The study employs a quantitative intellectual content analysis of articles published in 30+ scholarly LIS journals, following the design by Tuomaala et al. (2014). In the content analysis, we classify articles along eight dimensions covering topical content and methodology.

Findings - The topical findings indicate that the earlier strong LIS emphasis on L\&I services has declined notably, while scientific and professional communication has become the most popular topic. Information storage and retrieval has given up its earlier strong position towards the end of the years analyzed. Individuals are increasingly the units of observation. End-user's and developer's viewpoints have strengthened at the cost of intermediaries' viewpoint. LIS research is methodologically increasingly scattered since survey, scientometric methods, experiment, case studies and qualitative studies have all gained in popularity. Consequently, LIS may have become more versatile in the analysis of its research objects during the years analyzed.

Originality/value - Among quantitative intellectual content analyses of LIS research, the study is unique in its scope: length of analysis period (50 years), width ( 8 dimensions covering topical content and methodology) and depth (the annual batch of $30+$ scholarly journals).
\end{abstract}

Keywords Content analysis, Statistical analysis, Information science, Library and information science, Longitudinal study, Scholarly journal articles

Paper type Research paper

\section{Introduction}

Several studies indicate that (Library and) Information Science (LIS) is under reorientation both topically and methodologically (Hsiao and Chen, 2020; Ma and Lund, 2020). Pressures toward this are due to developments in underlying technologies of dissemination of information and in the corresponding research areas like digital libraries, data mining, machine learning and web science, among others. It is timely to investigate how these pressures materialize in the published LIS research.

To understand the state of a discipline, and consciously build its possible futures, it is necessary to know how the characteristics of its research have developed to date. This requires analysis of the development of research foci and methodological choices. Understanding the current state also helps planning the curricula and research. For the former one learns what courses are necessary, which strategically desirable, which minors are most useful and from where to recruit students and teachers. For research planning, one gains a mapping of the active research areas and hints for building successful alliances.

When building such understanding, past literature has analyzed research topics and methods in LIS (e.g. Aström, 2007; Tuomaala et al., 2014). The present paper reports a content analysis of articles published in top scholarly journals of LIS, following the study

(C) Kalervo Järvelin and Pertti Vakkari. Published by Emerald Publishing Limited. This article is published under the Creative Commons Attribution (CC BY 4.0) licence. Anyone may reproduce, distribute, translate and create derivative works of this article (for both commercial and non-commercial purposes), subject to full attribution to the original publication and authors. The full terms of this licence may be seen at http://creativecommons.org/licences/by/4.0/legalcode

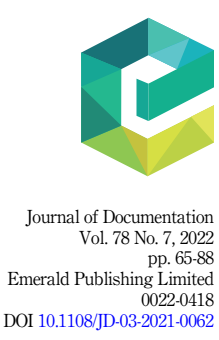

Received 19 March 2021 Revised 4 June 2021 Accepted 6 June 2021 
JD

78,7

66

design by Tuomaala et al. (2014) and covering research from 1965 to 2015 at 20 years' intervals.

The paper has two research questions (RQs): (1) What was the topical and methodological state of LIS research in 2015? We analyze this through articles published in core LIS journals in 2015. (2) How has LIS evolved from 1965 to 2015? We examine this in the light of comparable statistics for the years 1965, 1985 and 2005 and 2015, reporting on the rise and fall of LIS research foci and methodological choices.

Our dataset comes from scholarly English language LIS journals. Journal articles have been almost the sole data source in recent studies of LIS research publications (e.g. Milojevic et al., 2011; Figuerola et al., 2017; Han, 2020). We analyze the trends in LIS research over 50 years. The period covered is notably longer than in earlier studies, which typically cover about 20 years (e.g. Hou et al., 2018; Han, 2020), at most 36 years (Figuerola et al., 2017). To enhance comparability of findings with Tuomaala et al. (2014) we tried to keep the set of LIS journals stable over the years.

By following Tuomaala et al. (2014) we also adopted their criteria in journal selection. Their theoretically oriented criteria meant purposive selection of core journals matching the characterization of LIS as the provision of access to desired information (Vakkari, 1994). We have therefore avoided inclusion of journals belonging to other disciplines, like management information systems, as suggested by Abritzah et al. (2015) and Huang et al. (2019). Their practical criteria meant focusing on scholarly LIS journals with wide distribution, international editorial board and publication policy - which had been assessed as core journals by other researchers (e.g. by Peritz, 1980; Tuomaala et al., 2014). We arrived at a set of $30+$ journals for collecting an article set of 1,514 articles.

To construct the dataset for analysis, we performed a quantitative intellectual content analysis, classifying articles along eight dimensions covering their topical content and methodology. Our LIS classification is based on Tuomaala et al. (2014) and provides a tool for organizing and interpreting findings without an atheoretical selection and naming of topical clusters to represent LIS quite typical in scientometric analyses. In addition to the topical developments, we report on methodological developments of LIS during 50 years. Intellectual content analysis is appropriate in separating topical and methodological aspects. For example, it becomes natural to classify an article that topically belongs to scientometrics but employs a mathematical research strategy (non-empirical), and another topically in scientometrics but employs citation analysis (an empirical strategy).

\section{Literature review}

There are no recent major conceptual analyses of LIS like in earlier years (c.f. Tuomaala et al., 2014), while there are empirical ones. Most of these studies have applied scientometric research strategies, and only a few have used content analysis. Next, we will present studies which have analyzed LIS research after 2014.

\subsection{Research topics}

Ma and Lund (2020) is the only study using content analysis to explore the evolution of LIS. They analyzed the topics and methods of scholarly articles in 31 major LIS journals in 2006, 2012 and 2018, using categorizations of Tuomaala et al. (2014). The findings indicated a shift of emphasis toward scholarly communication and information seeking topics, along with a reduction of the share of information storage and retrieval (IS\&R) and L\&I service topics. In 2018 IS\&R was the most common research topic followed by scholarly communication.

Chang et al. (2015) analyzed the evolution of LIS based on keywords, bibliographical coupling and co-citation analyses during four five-year periods between 1995 and 2014. Data 
consisted of research articles in 10 major LIS journals. The cited top-5\% journal articles were analyzed. The authors reduced LIS intellectually from various numbers of clusters into four major fields. Information seeking and retrieval took the largest share of articles followed by bibliometrics in 1995-1999. In the later periods, the popularity of bibliometrics increased its share beyond $75 \%$ during $2005-2014$.

Liu et al. (2015) detected the topical structure of LIS in 2001-2013 by formal concept analysis. Data consisted of first authors and keywords of articles in 16 prominent LIS journals. Authors were chosen based on their productivity and impact. From the articles of the 60 key authors, 99 keywords with highest frequency were selected for the analysis. Nine main topics were identified: bibliometrics, scientometrics and informetrics, citation analysis, IR, information behavior, libraries, user studies, social network analysis, information visualization and webometrics.

Onyancha (2016) explored the evolution of LIS using author-supplied keywords in research articles between 1971 and 2015. Data were collected from Web of Science in the research area "Information Science Library Science". The results hint that the focus of LIS has changed from information system design and management in the 1970s to scientific communication, information retrieval, information management and user education by 2015. The data consist of a mix of articles representing management information systems and LIS due to the classification of research fields in WoS. In addition, only $26 \%$ of the articles included author-supplied keywords reducing the representativeness of the data. Authorsupplied keywords also run the risk of being inconsistent due to varying (or missing) keyword authority lists; low interest and motivation, and vague indexing skills on behalf of the authors. One may therefore ask to what extent the findings reliably reflect the evolution of LIS.

Figuerola et al. (2017) mapped the evolution of LIS in 1978-2014 by topic modeling. Their data included titles and abstracts of peer-reviewed publications in Lisa covering 92,705 items from 737 journals. Modeling produced 19 topics, which were grouped by human experts into four broader areas: process, information technology, libraries and specific areas of application. During the years topics associated with libraries lost in their share, while topics concerning searching and evaluation of search systems, and specific areas of application like digital humanities or informetrics, in particular, have gained weight.

Hou et al. (2018) analyzed the structure information science between 1996 and 2016 applying document co-citation analysis. They selected ten representative journals for the years 2009-2016 based on the journal co-citation analysis of JASIST, Scientometrics and Journal of Informetrics, while 12 core journals from an earlier study represented the earlier years. The results show that the core topics from 1996 to 2008 were IR, webometrics and citation behavior, while in the latter period scientometric indicators, citation analysis, scientific collaboration and information behavior, and particularly science evaluation indicators formed the core. Thus, the core topics in information science have developed towards scientific and professional communication (S\&PC). The results are biased towards scientometrics, because two-thirds of journals on which journal selection was based, represented scientometrics.

Li et al. (2019) surveyed LIS trends between 1989 and 2018 by document co-citation analysis. Data consisted of documents retrieved from Web of Science by the theme field "information science and library science". The output included 88,304 publications from 159 journals and proceedings. The study produced eight clusters: IR, social media, information systems, information behavior, bibliometrics and webometrics, science evaluation and knowledge management. IR, information systems and bibliometrics and webometrics are the oldest topics, while social media and science evaluation are the most recent ones. 
JD

78,7

68

Han (2020) investigated LIS evolution by analyzing journal articles using Latent Dirichlet Allocation. The explored period was between 1996 and 2019, which were divided into five sub-periods. For each period, 10 highest scoring LIS journals in journal ranking (JCR) were selected for analysis which focused on title, abstract and keywords in each article $(n=14,053)$. Ten clusters in each period were chosen for final analysis.

The results show that library service-related topics disappear after 1996-2005, while topics in IR proliferate during 2000-2010. Various topics in citation analysis and bibliometrics are well represented during the years. The topics belonging to information and knowledge management increase after 2005. The author divided the 10 topics into three larger fields in LIS: library science, bibliometrics and information science and other related issues. Library science disappeared after 2005, bibliometrics was a well-represented field until the last period, while information science and related issues were a strong field across the periods.

The results are biased in two ways. First, the highest-ranking journals varied greatly between the periods producing highly varied clusters. It is an open question how representative these topical changes are in LIS. Second, it has been shown that LIS journals in JCR represent two different fields: management information systems and LIS (Abritzah et al., 2015; Huang et al., 2019). The topical structures of these fields differ notably. Thus, the produced topical map of LIS contains topics from other fields.

Hsiao and Chen (2020) investigated LIS subfields between 2009 and 2018 by word bibliographic coupling. They selected 44 journals from JCR in the category "Information science, library science". They included only LIS journals, excluding journals belonging to management information systems. The data consisted of abstracts and author keywords in 21,066 articles. The observation period was divided into two: 2009-2013 and 20142018. The top-3 subtopics among 25 subtopics in both periods were scientific impact and research quality, information behavior and users and technology adoption. By grouping the subtopics, the study identified six main topics, including scholarly communication and scientometrics, information behavior and IR, applications of technology, library services and management, health information and technology and computer science techniques.

Miyata et al. (2020) applied Latent Dirichlet Allocation to identify LIS topics. They analyzed full texts of articles in five LIS journals in 2000-2002 and 2015-2017. Thirty topics in each period were labeled. The first period topics were grouped into six fields: IR (10 subtopics), information search and user (10), library (4), scholarly communication (4), library and information science (1) and bibliometrics (1). In 2015-2017, topics were grouped into five fields: IR (2 subtopics), information search and user (16), library (1), scholarly communication (6) and tweet analysis (5). In the first period, IR and information search (IS) included most topics, while in the second, the number of topics in IR decreased and in IS increased notably. In the field library, the number of topics decreased during the periods observed, while that of scholarly communication increased.

\subsection{Research methods}

Ma and Lund (2020) found that in LIS, experiment was the most popular method in 2006, 2012 and 2018 with a share of about $30 \%$. The second in popularity was survey. Its share increased from about $19 \%$ to $25 \%$. Citation analysis was the third with about a $13-14 \%$ share. The shares of the top research methods of the major topics of IR, information seeking, scholarly communication and L\&I services remained relatively stable across the data points. Experiment was the most common method both in IR and information seeking, while citation analysis dominated in scholarly communication, and survey in L\&I services. 
Chu (2015) identified research methods in LIS by analyzing research articles in Journal of Documentation, JASIST and LISR in 2001-2010. The four most common methods in all journals were theoretical approach, content analysis, questionnaire and experiment.

Ullah and Ameen (2018) provided a meta-analysis of methods applied in LIS based on 58 source publications published in 1980-2016. They created unifying categorizations of variables by re-coding method variables in the source publications. They found that empirical, descriptive and quantitative methods were used in most LIS research. Survey was the most popular strategy and descriptive statistics mostly used for data analysis.

\subsection{Summary}

During the last years, the topical structure of LIS has been analyzed almost solely by scientometric methods. Only one of the eight studies used content analysis. The topical structure of LIS varies between studies mostly due to the journal set and publications selected for analysis. The emerging main trend is the decline of library matters as research objects and the proliferation of scientometric topics. IR and information seeking have been popular research topics, but slightly losing in popularity. Empirical, descriptive quantitative studies have been the most common in LIS with survey as the most popular strategy.

\section{Research questions, data and methods}

\subsection{Research questions}

The paper has two main research questions (RQs) and several sub-questions (SQs) as follows:

$R Q 1$. What was the topical and methodological state of LIS research in 2015?

RQ2. How has LIS evolved from 1965 to 2015?

SQ1a-e: What are the shares of various (a) topics, (b) research strategies, (c) methods of data collection, (d) types of analysis and (e) types of investigation (or contributions) in LIS research in the year 2015?

SQ2a: How have the shares of article types (scholarly vs non-scholarly) evolved from 1965 to 2015 ?

SQ3a-e: How have the shares of various (a) topics, (b) viewpoints (c) social levels, (d) research strategies and (e) the application of research strategies within topics evolved from 1965 to 2015?

We investigate RQ1 through articles published in core LIS journals in 2015. The research design (concepts and methodology) and data are explained next in sections 3.2 and 3.3. We examine RQ2 in the light of comparable statistics for the years 1965, 1985, and 2005 and 2015, reporting on the rise and fall of LIS research foci and methodological choices. The paper contributes to our understanding of what LIS is and how it has evolved.

\subsection{Data}

A reliable account of LIS research based on publications requires data that includes all or a representative sample of research publications in the field. One has to define LIS to tell the difference to other disciplines, what characterizes research for excluding non-research publications and how to identify publications in LIS among all other publications.

Although it is difficult to find a definition of LIS satisfying all scholars, it is widely accepted that the unifying characteristic of LIS is the study on the provision of access to desired information (Vakkari, 1994). However, this brief characterization is challenging to operationalize. We set the criteria for what constitutes LIS research by the classification 
JD

78,7

70

system for LIS topics (Appendix 2): publications whose topic can be positioned within its classes belong to LIS. This solution has limitations, but using the same, although somewhat revised operationalization across the period examined fosters comparability of findings. Thus, our notion of LIS may not be shared by the entire LIS community, but it produces comparable results on the trends in LIS research.

In several leading journals, many authors come from other fields than LIS. One might suggest that LIS articles could be identified through their authors' disciplinary backgrounds. We think that an article's "LISness" must be determined topically - as being classifiable in the LIS classification and not by authors' background - because LIS is a crossroad of study fields rather than a tightly buttoned discipline.

There is nevertheless one limitation in the above notion of LIS - a rigid topical LIS classification becoming a straitjacket. If the classification does not evolve through omission of old, and/or addition of new (sub)classes over time, one may only analyse changes in relative weights of the originally selected classes. Such an approach does not welcome the evolution of LIS as a discipline and is blind to the growth of knowledge. Our classification of LIS topics originates from the one by Järvelin and Vakkari $(1990,1993)$ which they used for the analysis of LIS research in 1965, 1975 and 1985. It is now about 30 years old so it risks becoming anachronous. Therefore, we have revitalized the classification scheme by introducing new subclasses. However, major new developments do not necessarily fit in the classification but accumulate in the catch-all class "Another discipline" (Class $A=900)$.

We limit the publications to core scholarly journals in LIS which causes some bias in the results. Not all types of LIS research are equally well represented in journal articles as Sugimoto (2011) has noted. However, research articles form the core of the literature cited in LIS. Moreover, journal articles have been almost the sole source of data in recent studies of LIS research. Our aim to analyse a standard set of scholarly LIS journals over the years enhances comparability of findings. Naturally, we have included new journals under pressing needs and removed others which have ceased to exist (see Appendix 1).

Our unit of analysis is an article; we are not trying to describe the content profiles of journals, which function only as intermediate steps in reaching the articles. Therefore, the uneven productivity of journals in the number of articles is not problematic. However, changes in editorial policies of journals, or the in/exclusion of a prolific journal in a subarea (like the journal Scientometrics) certainly tilt the findings. Tuomaala et al. (2014) tackled this issue by presenting the key findings with and without the data derived through Scientometrics. We include this journal because there are compatible earlier results for 2005 and because there is no reasonable justification for selecting some proportion of articles in Scientometrics to represent this subarea in LIS. Scientometric studies have been considered as part of LIS by several scholars (e.g. Abritzah et al., 2015; Huang et al., 2019).

All journals are in English. This choice, while possibly causing some bias in the findings, is typical in analyses of LIS. The year 2015 volumes were taken as the sources of research articles - because it follows with the same interval (a decade) earlier analyses of LIS utilizing the same approach. Only potential research articles were collected (full articles, brief communications and critical reviews) and other texts (errata, letters-to-the-editors, book reviews, announcements and ads) were excluded. The basis of content analysis of each article was its metadata, i.e. title, abstract and keywords, or title and first page, depending on what was available. If an article proved impossible to analyse based on such metadata, its body text was consulted.

The total number of articles in the data for 2015 is 1,514. We excluded from the analysis articles which were classified as non-LIS studies $(A=900)(n=192)$ and non-scholarly articles $(n=112)$. The number of articles in the main analysis is thus 1,210 . 
The articles were classified according to eight dimensions (see Appendix 2):

Among them, LIS topic and Viewpoint represent the topical content, and Scholarliness indicates research articles that we focus on. The remaining five dimensions represent articles' methodological aspects. We discuss these dimensions, and their modifications briefly below.

Articles' topics were classified using the classification LIS topic. This classification system has been used widely (e.g. Hider and Pymm, 2008; Järvelin and Vakkari, 1990; Ma and Lund, 2020) and contains the following major classes:

000: LIS context (professions, history and publishing)

100: education in LIS

200: methodology

300: analysis of LIS
400: library and information-service (L\&I) activities 500: information storage and retrieval 600: information-seeking 700: scientific and professional communication 800: other aspects of LIS 900: another discipline

Classes 400-700 also have sub-classes. In view of the development of the field, the subclasses were conservatively updated on the basis of (Tuomaala et al., 2014) as follows:

(1) 020-The class library history was focused to history of L\&I institutions, activities or phenomena

(2) 030-Publishing was extended to cover even archival document and information history

(3) 410-The study of circulation and interlibrary loan activities was generalized to document delivery using documents in any physical forms and delivery means.

(4) 440-The study on user education was broadened to information literacy education (incl. information skills).

(5) 530-The subclasses of information search and retrieval were extended to cover studies in live collections as well.

(6) 534-The class on social media retrieval (e.g. Facebook, Twitter) was added.

We believe that these modifications, in contrast to the study by Tuomaala et al. (2014), serve maintaining the classification up-to-date and retaining comparability across the datasets.

Each article was classified under a single topical class; in the main classes 400-700, only the sub-classes were used for classification. When an article had many topics, its main topic was identified for classification. For instance, an article on education in information retrieval was classified as education and an article on information retrieval for education as information retrieval. The class "Other aspect of LIS" did not grow unduly large, which hints that it was possible to reliably select the major topic among the sub-topics of articles.

Scholarliness indicates whether the article reports scholarly research or not. The criterion for research is that the article reports on at least somewhat systematic approach to construct new concepts, knowledge and ideas (Peritz, 1980). This means that, typically, some research question is presented, some research method is identified and some results are acquired.

Classification of the viewpoint on information dissemination was based on traditionally recognized actors in the process of information dissemination (author, intermediary, end user, etc.) and their organizations. To classify we ask, whose needs, interests or opinions are analyzed in the study. The class $p=19$ for other viewpoint is a new class in the present paper.

The classification of social level differentiates among the individual, organizational and societal levels, also separating out multi-level analyses. The class individual was used when 
$\mathrm{JD}$

78,7

72

the objects studied in the article were individuals. For example, a study on intermediary behavior through analysis of search protocols has the social level individual. The class organizational was used when the objects studied in the article were organizations (e.g. library institutions, end-user institutions) even if the informants were individuals. The class societal was used when the objects studied in the article were, e.g. municipalities or societies. "Not applicable" was used when the objects studied in the article were at no level of social organization, as in studies of bibliometric laws or digital collections.

The methodological aspect of a study consists of research strategy, data-collection method, type of analysis and type of investigation. Research strategy is an overall approach to the study within which, for example, the decisions on data collection and the type of analysis are made. Among the typical strategies for empirical research are the historical, survey and qualitative strategy. The other main strategies are referred to as conceptual research strategy (e.g. verbal argumentation or concept analysis), mathematical or logical strategy and system and software analysis and design (Tuomaala et al., 2014).

In the original classification system of Järvelin and Vakkari (1990), evaluation and experiment were kept as different research strategies. However, for 2005, they were merged because both surveys and experiments may have elements of evaluation. In the present study they were kept separate. Therefore, the Variable $M$ (Research Strategy) has three new classes: $M=14$ (evaluation strategy), $M=22$ (experiment, incl. field experiment) and $M=29$ (other empirical strategy as a catch-all for any other qualitative or quantitative strategy), partially overlapping the earlier ones.

In empirical research the data are collected through various data-collection methods. These are listed in the classification Data-collection method. For the present analysis, this variable has two changes: new class $C=15$ (harvesting databases or their log files) and extended class $C=20$ (observation, incl. eye-tracking, screen capture, wearable recorders).

The classification Type of Analysis indicates whether the article reports qualitative, quantitative or mixed type of empirical research, or whether it is non-empirical.

Each article was classified under one content class for each variable $A, \ldots, I$. The data for 2015 were divided evenly between the researchers for classification. For reliability analysis, the researchers reclassified 31 articles independently. Reliability was calculated by means of Fleiss' Kappa, the value of which ranges from -1 for complete disagreement, to \pm 0 for random choices, and to +1 for complete agreement. Kappa values $0.41-0.60$ are moderate, $0.61-0.80$ good and $0.81-1.0$ very good. The agreement results are in Table 1 . The classifications of Scholarliness, Main topic, Topic, Social level, Type of analysis and Type of investigation have (at least) good agreement, while Viewpoint, Research strategy and Datacollection method have moderate. For $p$, a major source of inconsistency was $p=0$ vs $p=17$ (no viewpoint vs developer's viewpoint): often disagreement on methodology followed in lieuIs this paper mathematical, software or empirical, or a bit of all?

Table 1.

Analysis of

classification reliability - Fleiss' Kappa for two classifiers

\begin{tabular}{lccl}
\hline Variable & Fleiss' Kappa & $p$ & Agreement \\
\hline Topic & 0.619 & 0.000 & Good \\
Main topic & 0.684 & 0.000 & Good \\
Scholarliness & 0.631 & 0.000 & Good \\
Viewpoint on dissemination process & 0.555 & 0.000 & Moderate \\
Social level & 0.622 & 0.000 & Good \\
Research strategy & 0.532 & 0.000 & Moderate \\
Data-collection method & 0.603 & 0.000 & Moderate \\
Type of analysis & 0.852 & 0.000 & Very good \\
Type of investigation & 0.601 & 0.000 & Good \\
\hline
\end{tabular}


A plausible explanation for the moderate reliabilities is that classification of the viewpoint and methodology-related aspects based on article metadata often left much room for interpretation. Even scholarly articles in LIS core journals may be quite scarce in describing, in their metadata, the methods used in the study, and the body text does not always reveal the secret without serious effort unless the methods are well-established with a standard name tag.

\section{Findings}

4.1 Analysis of LIS articles

4.1.1 Topics. Table 2 indicates that S\&PC is the most popular major research topic $(37.4 \%)$ followed by IS\&R (22.9\%), L\&I service activities (13.9\%) and information seeking $(13.9 \%)$.

\begin{tabular}{|c|c|c|c|}
\hline \multirow[b]{2}{*}{ Topic } & \multicolumn{2}{|c|}{2015} & \\
\hline & Subtopic $\%$ & Main topic $\%$ & \\
\hline Professions & & 2.6 & \\
\hline Library history & & 1.2 & \\
\hline Publishing and book history & & 1.0 & \\
\hline Education in LIS & & 1.9 & \\
\hline Methodology & & 0.4 & \\
\hline Analysis of LIS & & 3.1 & \\
\hline L\&I service activities & & 13.9 & \\
\hline (1) Document delivery & 0.1 & & \\
\hline (2) Collections & 2.7 & & \\
\hline (3) Information or reference service & 1.0 & & \\
\hline (4) User education & 2.2 & & \\
\hline (5) Buildings and facilities & 0.4 & & \\
\hline (6) Administration or planning & 2.0 & & \\
\hline (7) Automation or digital libraries & 1.5 & & \\
\hline (8) Other L\&I service activities & 2.8 & & \\
\hline (9) Several interconnected L\&I activities & 1.2 & & \\
\hline IS\&R & & 22.9 & \\
\hline (1) Metadata/cataloguing & 1.2 & & \\
\hline (2) Classification and indexing & 4.0 & & \\
\hline (3) Text-retrieval methods & 3.7 & & \\
\hline (4) Retrieval methods in other media & 1.4 & & \\
\hline (5) Web retrieval methods & 1.6 & & \\
\hline (6) Social media retrieval & 1.2 & & \\
\hline (7) Digital information resources & 5.0 & & \\
\hline (8) Interactive (user-oriented) retrieval & 3.0 & & \\
\hline (9) Other aspects of IR & 1.8 & & \\
\hline Information-seeking & & 13.9 & \\
\hline (1) Information dissemination & 0.2 & & \\
\hline (2) Use/users of information channels/sources & 1.7 & & \\
\hline (3) Use of L\&I services & 1.7 & & \\
\hline (4) Task-based information-seeking & 3.7 & & \\
\hline (5) Other types of information-seeking studies & 2.5 & & \\
\hline (6) Information use & 0.8 & & \\
\hline (7) Information management & 3.2 & & \\
\hline S\&PC & & 37.4 & \\
\hline (1) Scientific or professional publishing & 12.9 & & \\
\hline (2) Citation patterns and structures & 7.6 & & \\
\hline (3) Web-metrics & 3.0 & & \\
\hline (4) Other aspects of communication & 14.0 & & Table 2. \\
\hline Other LIS topics & & 1.7 & Topics of LIS in 2015 \\
\hline Total & & 100.0 & $(n=1,210)(\%)$ \\
\hline
\end{tabular}


$\mathrm{JD}$

78,7

74

The four most frequently published major topics cover $88.1 \%$ of all scholarly articles. Other major topics were notably less popular with analysis of LIS (3.1\%) and professions $(2.6 \%)$ as most frequent research topics. The results show that in 2015 research published in journals accumulated heavily on S\&PC, which took almost four out of ten articles.

Most popular sub-topics within the major topics were other aspects of S\&PC (14.0\%) such as research assessments or various co-word analyses of research specialties. The next popular sub-topics were scientific and professional publishing $(12.9 \%)$, citation patterns and structures $(7.6 \%)$. These three most popular sub-topics belong to the area of S\&PC.

Within IS\&R the most studied sub-topics were digital information resources $(5.0 \%)$, classification and indexing (4.0) and text-retrieval methods (3.7\%). The proportion of interactive, user-oriented IR was only $3.0 \%$ of all research output. Neither had social media retrieval stimulated much interest $(1.2 \%)$ in 2015.

Within the area of information seeking task-based information seeking $(3.7 \%)$, information management $(3.2 \%)$ and other types of information seeking studies $(2.5 \%)$ (e.g. about serendipity) were the most popular sub-topics. Within L\&I service activities other L\&I service activities (2.8\%), collections $(2.7 \%)$ and user education $(2.2 \%)$ were the most frequently studied sub-topics.

4.1.2 Research strategies. Empirical research strategy $(72.7 \%)$ was notably the most popular of research strategies (Table 3). Conceptual $(10.5 \%)$ and mathematical or logical $(8.9 \%)$ research strategy were clearly less popular. Among empirical strategies survey $(23.9 \%)$ was the most common followed by other bibliometric strategy $(11.4 \%)$, case or action research strategy $(9.6 \%)$ and experiment $(5.9 \%)$.

Between the major topics, there were clear differences in methodological orientations. In L\&I services survey (37\%) dominated followed by the conceptual strategy $(18 \%)$. Within IS\&R mathematical or logical strategy $(25 \%)$ with experiment $(23 \%)$ were the most popular strategies. In information seeking survey was the topmost strategy $(46 \%)$, and then qualitative strategy (17\%). In S\&PC other bibliometric strategy (29\%) and survey $(20 \%)$ were the most common strategies.

\begin{tabular}{lcc}
\hline Research strategy & $\begin{array}{c}2015 \\
\text { Sub-strategy } \%\end{array}$ & $\begin{array}{c}2015 \\
\text { Major strategy \% }\end{array}$ \\
\hline Empirical research strategy & & 72.7 \\
(1) Historical method & 1.6 & \\
(2) Survey method & 23.9 & \\
(3) Qualitative method & 4.3 & \\
(4) Evaluation method & 2.6 & \\
(5) Case or action research method & 9.6 & \\
(6) Content or protocol analysis & 4.3 & \\
(7) Citation analysis & 5.5 & \\
(8) Other bibliometric method & 11.4 & \\
(9) Secondary analysis & 0.4 & 5.9 \\
(10) Experiment (incl. Field experiment) & 5.9 & 2.1 \\
(11) Other empirical method & 3.3 & 0.8 \\
Conceptual research strategy (31 + 32) & & 100.0 \\
Mathematical or logical & & \\
System/software analysis/design & & \\
Literature review & & \\
Bibliographic & & \\
Other strategy & & \\
Total & &
\end{tabular}

Table 3.

Research strategies in $2015(n=1,210)(\%)$ 
4.1.3 Methods of data collection. Reflecting the two most popular research strategies, survey and other bibliometric strategy, most popular data collection techniques were questionnaire or interview (17.9\%) and citation data collection (26.5\%) (Table 4). IR experiment $(11.3 \%)$ and multiple methods of collecting data $(11.8 \%)$ were also popular techniques.

In studies on L\&I services data were mostly collected through questionnaires or interviews $(29.8 \%)$, by combining several techniques or by collecting items for content analysis $(11.3 \%)$. IR experiment $(48.0 \%)$ was clearly the most frequent data collection technique in IS\&R followed by combined data collection methods $(10.1 \%)$ and questionnaires or interviews $(7.9 \%)$. In information seeking the use of questionnaires or interviews $(53.6 \%)$ dominated before several data collection methods $(20.8 \%)$ or other data collection methods (7.1\%). In S\&PC data were collected in $70.4 \%$ of cases by citation data collection methods.

4.1.4 Type of analysis and type of investigation. Quantitative analysis $(67.4 \%)$ was in the articles the main-stream approach, while qualitative $(13.6 \%)$ and mixed $(5.5 \%)$ approaches were small brooks. In IS\&R (71.8\%) and in S\&PC (91.4\%) quantitative analysis was almost the sole approach, while in L\&I services qualitative analysis (23.2\%) had gained footing besides quantitative analysis (47.6\%). The same holds in information seeking (32.1\% vs $46.4 \%)$.

Empirical research $(78.9 \%$ ) was the most common research type (Table 5). The emphasis was on descriptive studies $(54.7 \%)$, while comparative $(16.4 \%)$ and explanatory $(7.8 \%)$ studies were in the clear minority. Among non-empirical studies, the methodological $(6.4 \%)$,
LIS research across 50 years

Data-collection method $\quad \%$

Questionnaire or interview(s)

Harvesting databases or log files $\quad 2.3$

$\begin{array}{lr}\text { Observation } & 0.1 \\ \end{array}$

$\begin{array}{lr}\text { Thinking aloud } & 0.2 \\ \text { Content analysis (item collection) } & 6.0 \text {. }\end{array}$

$\begin{array}{lr}\text { Content analysis (item collection) } & 6.0\end{array}$

\begin{tabular}{lr} 
Citation data collection & 26.5 \\
\hline
\end{tabular}

$\begin{array}{lr}\text { Historical source analysis } & 1.7\end{array}$

$\begin{array}{lr}\text { Several methods of collection } & 11.8\end{array}$

Use of data collected earlier $\quad 3.6$

IR experiment $\quad 11.3$

Other data-collection method $r .3$

Not applicable $r .2$

\begin{tabular}{lr} 
Total & 100.0 \\
\hline
\end{tabular}

Table 4.

Data-collection methods in 2015 $(n=1,210)(\%)$

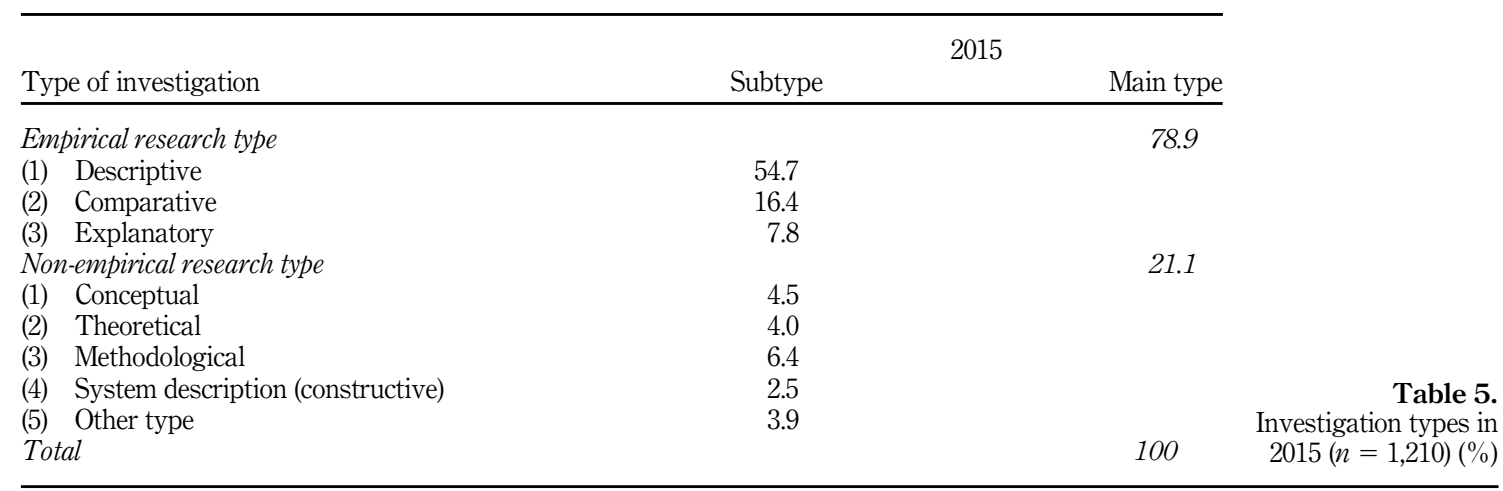


$\mathrm{JD}$

78,7

76

conceptual (4.5\%) and theoretical (4.0\%) ones were most popular, although their share in the whole population was modest.

Descriptive studies were clearly most common in L\&I services $(59.5 \%)$, information seeking $(60.7 \%)$ and S\&PC $(63.7 \%)$, while comparative ones $(37.9 \%)$ in IS\&R followed by descriptive studies (32.9\%). Interestingly, in information seeking explanatory studies $(22.0 \%)$ were relatively common, whereas methodological studies $(11.3 \%)$ had gained some footing among studies on S\&PC.

\subsection{Analysis of trends in LIS across 50 years}

The proportion of research articles among all articles has grown linearly from $30 \%$ to $91 \%$ during the period studied (Table 6). The growth has been rapid especially during the last 10 years compared to earlier 20-year periods. Tuomaala et al. (2014) is the source for the year 1965, 1985 and 2005 data throughout the section.

This means that even if the roots of LIS may lie in the professions, LIS has matured as a scholarly discipline. While the number of articles in core LIS journals grows notably, even the number of professional articles diminishes significantly - from over 300 in 1965 to just over 100 in 2015. Such articles may be submitted to professional journals reflecting the division of labor between scholarly and professional journals, or the acceptance thresholds may have become more stringent.

In the following we focus on trends based on research articles in LIS.

4.2.1 Topics. The most striking development is the rise of S\&PC research from about a $5 \%$ share in 1965 to close to $40 \%$ in 2015 (Table 7). The proportion of S\&PC increased strongly in 2005, because the journal Scientometrics was included in the journals studied. Thus, in a sense the rise is technical, although it clearly reflects the popularity of S\&PC within LIS; in 2015 it was the most popular broad topic. This is due to the active publication policy of "Scientometrics". The number of scholarly articles in this journal in 2015 was 344. This was the highest among all journals in the data.

\begin{tabular}{lcccc}
\hline Article type & $1965(n=467)$ & $1985(n=833)$ & $2005(n=848)$ & $2015(n=1,322)$ \\
\hline Scholarly & 30 & 54 & 72 & 91 \\
Professional & 70 & 46 & 28 & 9 \\
Total & 100 & 100 & 100 & 100 \\
\hline
\end{tabular}

Table 7.

Main topics in 1965-2015 (\%)

\begin{tabular}{lcccc}
\hline LIS topic & $1965(n=142)$ & $1985(n=449)$ & $2005(n=718)$ & $2015(n=1,210)$ \\
\hline Professions & 4.9 & 5.6 & 1.4 & 2.6 \\
Library history & 2.8 & 3.8 & 4.2 & 1.2 \\
Publishing & 5.6 & 3.1 & 0.6 & 1.0 \\
Education in LIS & 2.1 & 4.7 & 0.3 & 1.9 \\
Methodology & 7.8 & 0.9 & 0.6 & 0.4 \\
Analysis of LIS & 5.6 & 2.4 & 2.8 & 3.1 \\
L\&I service activities & 25.4 & 27.2 & 17.0 & 13.9 \\
IS\&R & 32.4 & 29.2 & 30.1 & 22.9 \\
Information-seeking & 7.8 & 6.0 & 12.3 & 13.9 \\
S\&PC & 4.9 & 7.3 & 24.3 & 17.4 \\
Other LIS topics & 1.0 & 10.2 & 6.4 & 100.0 \\
Total & 100.3 & 100.0 & 100.0 & \\
\hline
\end{tabular}


IS\&R and L\&I service activities have been the largest areas of research from 1965 to 2005, while S\&PC has overtaken L\&I service activities in 2005 and conquered the largest position in 2015. The share of IS\&R - the earlier largest topic - has decreased from $32.4 \%$ to $22.9 \%$ during the time period observed. The share of L\&I service activities has decreased also notably from $25.4 \%$ to $13.9 \%$. By contrast, the proportion of studies on S\&PC has increased in particular during the last two observation periods. Although the shares of articles in various topics have decreased during the years, their absolute numbers have increased notably. Although, e.g. L\&I service activities, is not relatively as popular a topic as it used to be, there is more research on it than earlier. The general expansion of research activities is behind these trends.

Information seeking has been relatively popular research topic during the years. Its share has stabilized around $12-14 \%$ in the last two periods. The share of articles in the remaining major topics is substantially smaller varying between $5 \%$ and $1 \%$. Less frequent main topics have lost their attraction as research objects within research community. This has happened mostly in the twenty-first century. This diminishing trend has been associated with the growth of the four most studied research areas - L\&I services, IS\&R, information seeking and S\&PC. Their proportion has increased from $73.4 \%$ to $88.1 \%$ between the years.

4.2.2 Most frequent topics. There is a clear change in the composition of the six most popular topics during the observed period (Table 8). The minor topics and sub-topics in L\&I services have lost their popularity, while sub-topics in IS\&R and S\&PC have gained it especially after 2005.

In 1965 there was a strong emphasis on classification and indexing $(21.8 \%)$, but also automation $(7.8 \%)$, collections $(6.3 \%)$, methodology $(7.8 \%)$ and analysis of LIS $(5.6 \%)$ attracted attention. In 1985 problems of IS\&R gained diversified attention focusing on IR $(12.7 \%)$ and classification and indexing $(5.6 \%)$. L\&I services were represented in top six topics by collections $(7.1 \%)$ and administration (5.8\%). In 2005 reflecting the popularity of IS\&R, interactive IR (7.7\%), classification and indexing $(7.1 \%)$ and web retrieval $(4.6 \%)$ were among the top six topics. S\&PC had gained also popularity so that other topics in S\&PC $(10.4 \%)$ and citation structures $(6.5 \%)$ had penetrated among topmost topics. In 2015 the three top positions were conquered by the sub-topics of S\&PC - other S\&PC (14.0\%), scientific publishing $(12.9 \%)$ and citation structures (7.6\%). IS\&R was represented also by three topics, digital information resources $(5.0 \%)$, classification and indexing $(4.0 \%)$ and text retrieval $(3.7 \%)$.

4.2.3 Viewpoint on information dissemination. During the years, it has been very typical to analyze research objects regardless of the viewpoint on information dissemination (Figure 1), in studies on IS\&R and S\&PC in particular. This is likely due to active technological development foci in information interaction and process-neutrality of many scientometric studies.

The change from intermediary's viewpoint to end-user's and developer's viewpoint has occurred in the period observed. Intermediary's angle was dominant in 1965 and 1985 (35\%

\begin{tabular}{|c|c|c|c|c|c|c|c|c|}
\hline \multicolumn{2}{|l|}{$1965(n=142)$} & \multicolumn{2}{|c|}{$1985(n=449)$} & \multicolumn{2}{|c|}{$2005(n=718)$} & \multicolumn{2}{|c|}{$2015(n=1,210)$} & \\
\hline Classif and index & 21.8 & Inf retrieval & 12.7 & Other sci comm & 10.4 & Other sci comm & 14.0 & \\
\hline Automation & 7.8 & Collections & 7.1 & Interactive IR & 7.7 & Sci publishing & 12.9 & \\
\hline Methodology & 7.8 & Administration & 5.8 & Classif and index & 7.1 & Citation struct & 7.6 & \\
\hline Collections & 6.3 & Professions & 5.6 & Automation & 6.4 & Digit info res & 5.0 & Table 8. \\
\hline Analysis of LIS & 5.6 & Classif and index & 5.6 & Citation struct & 6.5 & Classif and index & 4.0 & The six most popular \\
\hline Publishing & 5.6 & Education LIS & 4.7 & Web retrieval & 4.6 & Text retrieval & 3.7 & topics in \\
\hline Total & 54.9 & Total & 41.5 & Total & 42.7 & Total & 47.2 & $1965-2015(\%)$ \\
\hline
\end{tabular}


$\mathrm{JD}$ 78,7

78

Figure 1.

Views on the information dissemination phase in 1965-2015 (\%)
60

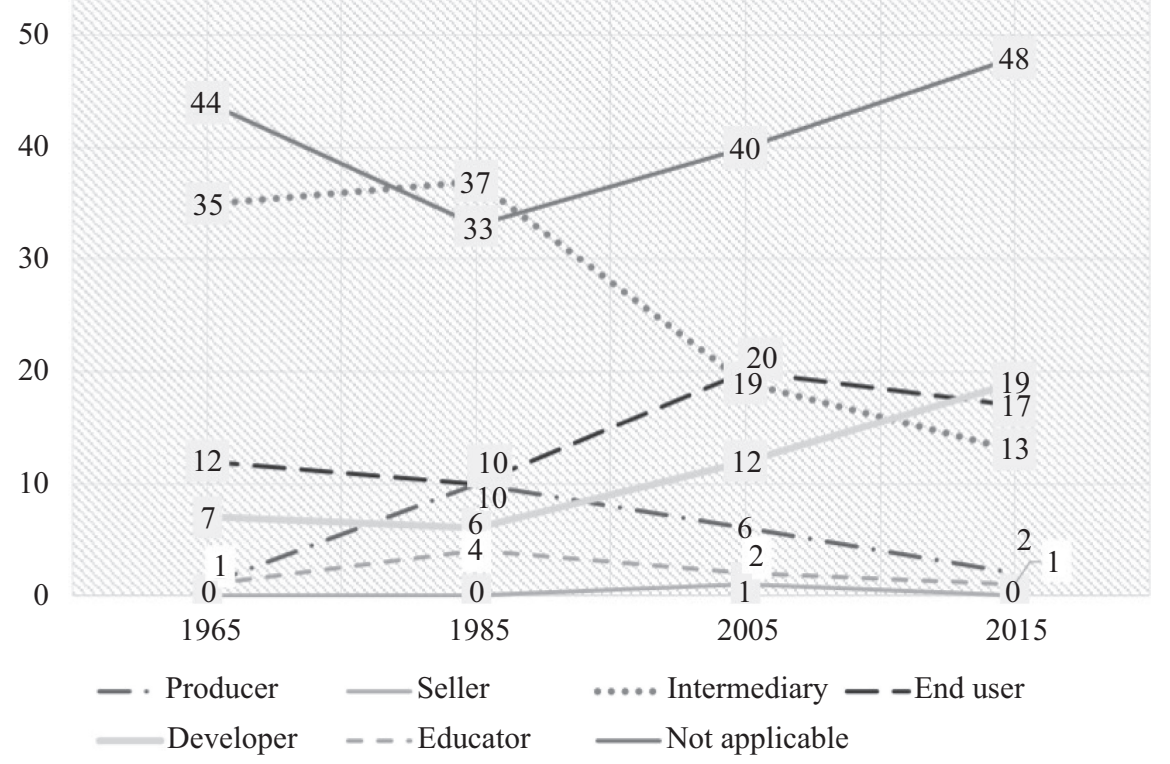

and $37 \%$ respectively), while end-user's (12\% and $10 \%)$ and developer's $(7 \%$ and $6 \%)$ viewpoints were minor ones in this period. Producer's angle was also at its highest in 1985. The dominance of intermediary's and producer's viewpoints may reflect the active development of the online industry and intermediary's profession at that time.

Not until 2005 onwards the end user's and developer's viewpoints bypassed the intermediary's position. In 2015 developer's angle with the share of $19 \%$ was somewhat more popular than the end user's angle with the share of $17 \%$. The gradual change of focus from intermediary's perspective to end-user's and developer's perspectives reflects the changes in the emphasis of research from L\&I services (intermediary) to IS\&R (developer) and information seeking (end-user).

4.2.4 Social level. Studies focusing on individuals have a growing trend, more than doubling from $13 \%$ to $28 \%$ during the period observed (Figure 2). The organizational level of analysis peaks in $1985(26 \%)$ and declines thereafter. These trends reflect the changing focus of research from L\&I services (organizations) to information seeking (individuals). Society level or multi-level analyses are infrequent (under $10 \%$ share) during the whole period. The clearly dominant class is "not applicable", with a share over $50 \%$ almost the whole period, signaling the popularity of artifacts and ideas as objects of study in LIS.

4.2.5 Research strategies. Empirical studies dominate LIS - their trend is rising from around $50 \%$ in the early years to over $70 \%$ in the later years (Table 9). Of the other major strategies, the conceptual strategy starts at close to $30 \%$ share in 1965 but shrinks to $10 \%$ by 2015. The math/logical strategy has minor popularity and a flat trend initially but gains a lot for the final year $(8.9 \%)$. This may be due to the popularity of machine learning and data mining in IS\&R. Constructive systems-oriented articles peak in $1985(14.5 \%)$ and follow a declining trend after that, ending at $5 \%$ in 2015.

Among empirical strategies survey has been through the years the most popular one with a share about one-fourth, while bibliometric methods have gained footing during the two last 


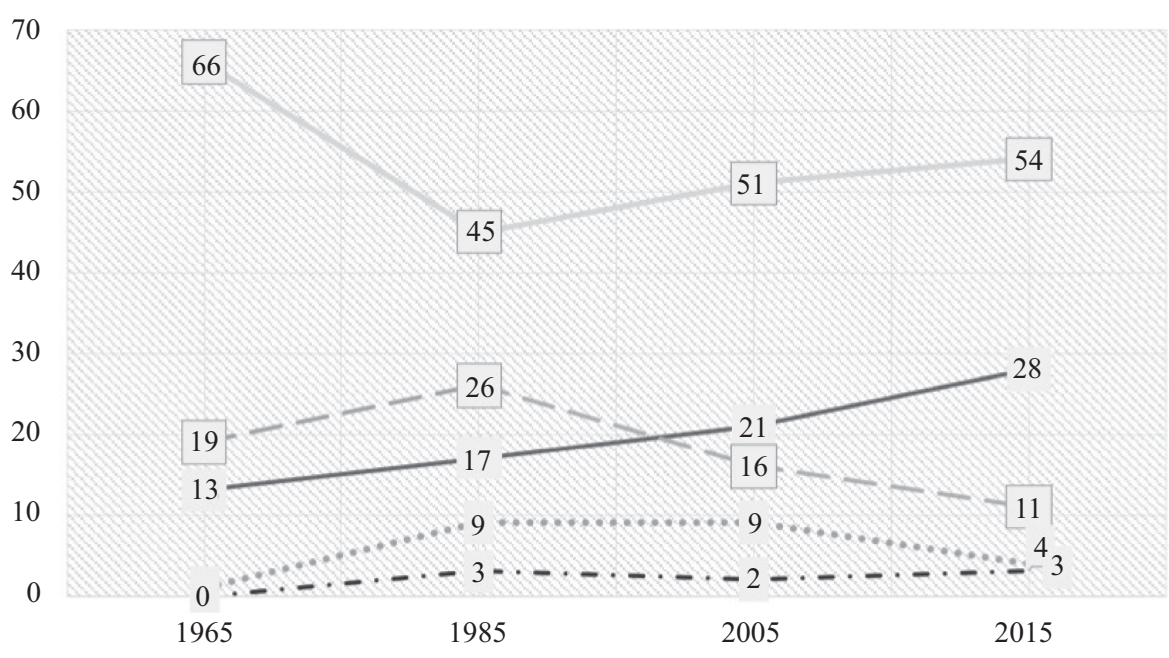

— Individual — - Organizational..... Societal - - - Multi-level —— Not applicable

\section{Research strategy}

Empirical research strategy

(1) Historical method

(2) Survey method

(3) Qualitative method

(4) Evaluation

(5) Case or action research method

(6) Content or protocol analysis

(7) Citation analysis

(8) Other bibliometric method

(9) Experiment

(10) Other empirical method

Conceptual research strategy

Mathematical or logical

System/software analysis/design

Literature review

Other

Total

$1965(n=142) \quad 1985$

48.5

10.6

22.5

0.7

9.8

2.8

0.0

0.0

0.7

3.5

1.4

28.9

3.5

9.2

4.9

4.9

99.9

$985 n=$
56.0
10.7
22.9
1.6
7.2
3.8
1.1
3.3
0.9
1.6
4.5
23.4
2.7
14.5
2.7
0.0
99.3

Figure 2. The social level in $1965-2015(\%)$
LIS research
across 50 years

79

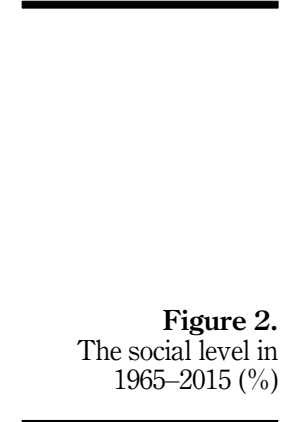

periods reaching the share of about $15 \%$. The increase in the proportion of studies on S\&PC is naturally reflected in the growing share of bibliometric methods. Evaluation has been uniformly popular with a share of tenth until 2015 when its share drops to $2.6 \%$. Qualitative, case/action research, content analytic, bibliometric strategies and experiment all have a rising trend. Case studies and experiments in particular, have increased their popularity. Diverging from the previous, historical method has a downward trend from $10.6 \%$ in 1965 to $1.6 \%$ in 2015.

4.2.6 Data collection methods. Questionnaire or interview are popular through the years, other data collection methods and historical method lose their popularity, while citation analysis, IR experiment and multiple data collection methods gain popularity (Table 10). 
$\mathrm{JD}$
78,7

80

Table 10.

Data-collection

methods in

1965-2015 (\%)

( $*$ indicates $<0.5 \%$ )

Method

$1965(n=142)$

$1985(n=449)$

$2005(n=718)$

$2015(n=1,210)$

Questionnaire or interview

Observation

Thinking aloud

Content item collection

Citation data collection

Historical source analysis

Several methods

Data collected earlier

IR experiment

Other collection method

Not applicable

Total

17
0
0
0
0
11
2
4
19
48
101

17

1

0

2

4

11

2

5

15

43

100

16

*

3

3
6

6
5

14

5

17

9

25

100
18

*

6

27

2

12

4

11

5

15

Questionnaires/interviews are employed by one in six studies through the years, which makes it as a constantly common data collection method. The popularity of other methods varies over time. Content collection for analysis $(0 \% \rightarrow 6 \%)$, citation collection for analysis $(0 \% \rightarrow 27 \%)$ and multiway data collection $(2 \% \rightarrow 12 \%)$ all gain in popularity. The popularity of citation analysis in 2015 reflects the growing share of studies on S\&PC among the articles. The declining trend of IR experiment likely reflects the decreasing proportion of articles on IS\&R.

4.2.7 Application of strategies in topics. Table 11 shows the popularity of research strategies in the four main topical areas. In L\&I service research, survey in particular, but also conceptual strategy has been dominant over the years. Survey has also been the most popular strategy in information seeking, although its share has declined from $78 \%$ in 1965 to $46 \%$ in 2015. This decline is associated with the increasing use of qualitative strategy in this topic. In IS\&R, evaluation/experimentation and software analysis/design are persistent in popularity with a joint share of $37 \%-77 \%$ in the last three periods. This corresponds to the wide-spread

\begin{tabular}{|c|c|c|c|c|c|c|c|c|c|}
\hline \multirow{3}{*}{$\begin{array}{l}\text { LIS topic } \\
\text { L\&I service } \\
\text { activities }\end{array}$} & \multirow{3}{*}{$\begin{array}{l}\text { Pop } \\
\text { I } \\
\text { II }\end{array}$} & \multicolumn{2}{|c|}{$1965(n=142)$} & \multicolumn{2}{|c|}{$1985(n=449)$} & \multicolumn{2}{|c|}{$2005(n=718)$} & \multicolumn{2}{|c|}{$2015(n=1,210)$} \\
\hline & & Survey & 36 & Conceptual & 28 & Survey & 45 & Survey & 28 \\
\hline & & $\begin{array}{l}\text { System/ } \\
\text { SW }\end{array}$ & 14 & Survey & 25 & Conceptual & 17 & Conceptual & 18 \\
\hline & III & $\begin{array}{l}\text { Other } \\
\text { empir }\end{array}$ & 11 & Historical & 13 & $\begin{array}{l}\text { Case or } \\
\text { action }\end{array}$ & 12 & Content anal & 7 \\
\hline \multirow[t]{3}{*}{ IS\&R } & I & Conceptual & 50 & $\begin{array}{l}\text { System/ } \\
\text { SW }\end{array}$ & 31 & $\begin{array}{l}\text { Evaluation/ } \\
\exp \end{array}$ & 63 & Mathematical & 22 \\
\hline & II & $\begin{array}{l}\text { eval./ } \\
\text { system }\end{array}$ & 11 & Conceptual & 29 & System/SW & 14 & Experiment & 21 \\
\hline & III & & & Evaluation & 12 & Survey & 9 & System/SW & 16 \\
\hline \multirow{3}{*}{$\begin{array}{l}\text { Information- } \\
\text { seeking }\end{array}$} & $\mathrm{I}$ & Survey & 73 & Survey & 67 & Survey & 46 & Survey & 44 \\
\hline & II & $\ldots$ & & Conceptual & 11 & Conceptual & 18 & Qualitative & 17 \\
\hline & III & $\ldots$ & & $\begin{array}{l}\text { System/ } \\
\text { SW }\end{array}$ & 11 & Qualitative & 18 & $\begin{array}{l}\text { Other } \\
\text { empirical }\end{array}$ & 7 \\
\hline \multirow{3}{*}{$\begin{array}{l}\text { Scientific and } \\
\text { professional } \\
\text { communication }\end{array}$} & I & Conceptual & 43 & $\begin{array}{l}\text { Citation } \\
\text { anal }\end{array}$ & 39 & Survey & 30 & $\begin{array}{l}\text { Other } \\
\text { bibliomet }\end{array}$ & 28 \\
\hline & II & Historical & 29 & Conceptual & 21 & $\begin{array}{l}\text { Citation } \\
\text { anal }\end{array}$ & 26 & Survey & 20 \\
\hline & III & $\ldots$ & & Survey & 15 & $\begin{array}{l}\text { Other } \\
\text { bibliomet }\end{array}$ & 15 & Case study & 19 \\
\hline
\end{tabular}

Table 11.

The three most popular research strategies for topics in 1965-2015

$(\%)$ (* indicates $n<10$ ) 
view that "evaluation is the hallmark of IR". Citation analysis/other bibliometric strategy and survey dominate the fourth main area, S\&PC (47\%-54\% since 1985).

\section{Discussion}

In the 50 years observed both the proportion and absolute number of research articles in core journals of LIS have increased notably. When in $196530 \%$ of the articles were scholarly in nature, the respective figure in 2015 was $91 \%$. This hints to the maturation of LIS as a field of research, which may also reflect possibly tightened acceptance requirements of journals. The large growth in absolute number of research articles means that also the research activity in LIS in general has increased. Although the proportion of some research topics like L\&I service activities decreases compared to other topics, still the research activity in that topic may be greater than earlier.

\subsection{Research question $R Q 1$}

In 2015, S\&PC took the lion's share in the topical profile of LIS, 37.4\% of all publications. IS\&R came second $(22.9 \%)$ followed by L\&I services $(13.9 \%)$ and information seeking $(13.9 \%)$. Thus, there were clear differences in popularity between the major topics in LIS. The other major topics in the classification like professions, library history or analysis of LIS were much less frequent areas covering a few percentages each.

The popularity of S\&PC reflects the growing interest in research community toward scientometric analyses. This has led to an increase in the number of articles, e.g. in the journal Scientometrics. It covers 344 articles in our data, which is the largest share among journals observed. Removing Scientometrics from the analysis would change the rank of S\&PC from first $(37.4 \%)$ to fourth $(13.6 \%)$, and rank IR $(31.2 \%)$, L\&I service activities $(19.4 \%)$ and information seeking (19.4\%) one step higher. However, S\&PC has been an essential part of LIS at least from the time of Eugene Garfield and Institute for Scientific Information founded in 1950s. Therefore, it is justified to include a journal representing this sub-field of LIS in the data.

In little over one-half of the studies it was neither possible to identify a viewpoint to information dissemination nor the social level. The former was in part due to the large share of publications in S\&PC without viewpoint. Typical in these articles was an emphasis on structural relationships rather than problems faced by some actors. The latter was due to a large proportion of articles in S\&PC and IS\&R without social level. This is likely due to the popularity of research on technical solutions in the field, ignoring a social level of analysis.

The most frequent viewpoints were developer's, end-user's and intermediary's viewpoints. Intermediary's viewpoint (52.4\%) was emphasized in studies on L\&I services, whereas developer's viewpoint (48.7\%) was emphasized in studies on IS\&R, and end-user's viewpoint $(57.7 \%)$ in studies on information seeking. The most common social level in articles was the individual's (28.4\%), followed by the organizational (11.4\%). Individual level was most popular in studies on information seeking, while L\&I services were, unsurprisingly, approached from the organizational perspective.

Empirical research strategy $(72.7 \%)$ was the dominant one, while conceptual $(10.5 \%)$ and mathematical/logical (8.9\%) strategies were clearly less popular. Among empirical strategies, survey was the most common (23.9\%) followed by other bibliometric strategy (11.4\%). There were clear differences in methodological orientations between topics. Within IS\&R, mathematical/logical strategy $(25 \%)$ with experiment $(23 \%)$ were the most popular strategies, while in information seeking, survey $(46 \%)$ and qualitative strategy $(18 \%)$ flourished. Reflecting the two most popular research strategies, survey and other bibliometric strategy, the most popular data collection methods were questionnaire or interview $(17.9 \%)$ and citation data collection (26.5\%). 
JD

78,7

82

\subsection{Research question RQ2}

The trends in LIS research observed in the model study (Tuomaala et al., 2014) have either strengthened or stabilized. During the last period, S\&PC has become the largest research area in LIS with a share of about 37\%. The largest research topic until 2005 was IS\&R. Its share has declined from about $30 \%$ until 2005 to $23 \%$ in 2015 . L\&I services have lost their strong position especially in 2005 and 2015 to the level of 14\%, while information seeking has increased and stabilized its share to around 14\%. For 50 years, research in LIS has increasingly accumulated on these four major topics from about $75 \%$ to $90 \%$. Among the six most popular sub-topics a similar 50-year accumulation can be observed. The most popular topics come increasingly from S\&PC or IS\&R.

The findings about the largest research areas in LIS are in line with earlier studies, which confirm the earlier findings. A more detailed comparison of sub-topics is not possible due to the differences in categorizing topics and sub-topics. Several studies, however, indicate a decline in the share of studies on L\&I services, while reporting a steady growth in studies on S\&PC, or a declining stabilization in studies of IS\&R. S\&PC is the largest research area followed by IS\&R (Chang et al., 2015; Figuerola et al., 2017; Han, 2020; Ma and Lund, 2020). Ma and Lund (2020) also report findings corresponding to ours that the top research method in IS\&R is experiment, in L\&I services survey and in S\&PC citation analysis.

The topical changes are reflected in other aspects of research too. Intermediaries' and their organizations' viewpoints have yielded to end users' and their organizations' viewpoints. During the last period, in particular the developer's view has strengthened in research. In addition, studies on the individual level of analysis have gained footing, while organizational or societal level in analyses has diminished. This reflects the increase in end-user searching and in the use of tools designed for that purpose.

The role of empirical research strategy has strengthened in LIS. Although survey has a constant major role, an increase in the use of bibliometric methods and case studies has enhanced the position of empirical research strategies. Citation data collection has become the most popular data collection method, reflecting the popularity of S\&PC as a research topic. IR experiment as data collection method has lost some of its standing due to the shrinking share of IS\&R research. A positive sign has been the growing use of multiple methods in data collection. It seems that pluralism in the use of research strategies has strengthened. While in 2005 in three major research topics one research strategy dominated, in 2015 this held only in one topic. Thus, the research strategies had distributed more evenly across major topics than earlier. In all, our results suggest, that although research in LIS has accumulated in major research areas, versatile use of research methods has increased in these areas. As a consequence, the account of research objects may have become more comprehensive.

The findings in this study help planning teaching in LIS by indicating continuously active and currently hot topics of research and ways of approaching them methodologically. - For example, experimental design and citation analysis seem useful skills. In addition, the findings, and our approach to content analysis help research development through identifying, which topics have (not) been studied and which approaches have (not) been employed. In fact, the classification system for content analysis can be seen as a multi-dimensional study design generator: each cell is a junction of topical and methodological choices.

A field of research may institutionalize both cognitively and socially (Whitley, 1984). The former means a shared and coherent understanding of principal research problems and goals, ways of conceptualizing the research objects and methodologies to study them. The latter refers to, e.g. university departments, journals and conferences representing the field of research.

It is questionable whether the 50 years have led to cognitive institutionalization in LIS as a whole. There hardly exists a shared understanding of principal research problems and goals. Among the major research topics, the professionally motivated core, L\&I activity research, 
shrinks and fosters an endemic viewpoint (of intermediaries). In the other three major topics, the end-user's, developer's and no viewpoint are more common. This may indicate that the major thrust of $\mathrm{R} \& \mathrm{D}$ in dissemination of information is around dissemination-process reengineering, not on its historical (or contemporary) forms. The other three major areas rather work with strongly institutionalized external disciplines than develop shared research problems, goals and approaches - S\&PC with Science Studies, IS\&R with Computer Science (cf. Chang, 2018) and Information Seeking with application fields like Medicine or Health Sciences (Deng and Xia, 2020) or Communication Studies and social sciences more generally. These other disciplines do not necessarily share the research goals of LIS sub-fields. It may be that the growing interest of other disciplines toward research problems relevant to LIS combined with the growing interest of some major journals in the field to publish papers belonging to the adjacent fields disintegrates LIS. Interdisciplinarity is fruitful in developing new knowledge, but isn't here a risk for LIS being absorbed by the stronger partners - both cognitively and socially? Further study is needed to analyse these questions.

\subsection{Limitations}

The dataset and type of analysis of the present study bring some inherent limitations to the findings, which are in part discussed in the section on data. It is debatable how representative the (selected) core scholarly LIS journals are for LIS research. There are also conferences that could be sources of LIS papers and therefore change the relative shares of some topics. The frequencies of topics do not inform about the content and evolution of research labeled by the topic names. Finally, the moderate reliability values of some variables hint to care required in interpreting our results.

\section{Conclusion}

Research in LIS has experienced structural changes during 1965-2015. In the topical profile of LIS, the earlier strong emphasis on L\&I services has declined notably, while S\&PC has become the most popular topic. IS\&R has kept its essential position, although its relative popularity has decreased during the last ten years analysed. Individuals are increasingly, but organizations decreasingly, the units of observation in the studies. Moreover, intermediaries' view on information dissemination process has yielded to end-user's view and recently to developer's view. These changes are due to reorientation in LIS from L\&I service organizations to information seeking and searching by individuals and development of tools for this.

Methodological changes also reflect changes in LIS topics. The popularity of empirical research strategies has grown, while conceptual strategies have lost interest. Survey, scientometric methods, experiment, case studies and qualitative studies have gained in popularity, while historical method has lost. Survey is an all-round strategy popular in information seeking, S\&PC and L\&I services. Experiment is typical in IS\&R, while scientometric methods are typical in S\&PC. Interestingly, although research in LIS is topically accumulating increasingly into four major research topics, methodologically it is scattering increasingly into many approaches. Consequently, it is likely that LIS research has created a more versatile and valid account of its research objects during the years analysed.

\section{References}

Abrizah, A., Noorhidawati, A. and Zainab, A.N. (2015), "LIS journals categorization in the journal citation report: a stated preference study", Scientometrics, Vol. 102 No. 2, pp. 1083-1099.

Åström, F. (2007), "Changes in the LIS research front: time-sliced cocitation analyses of LIS journal articles, 1990-2004", Journal of the Association for Information Science and Technology, Vol. 58 No. 7, pp. 947-957. 
$\mathrm{JD}$

78,7

Chang, Y.-W. (2018), "Examining interdisciplinarity of library and information science (LIS) based on LIS articles contributed by non-LIS authors", Scientometrics, Vol. 116 No. 3, pp. 1589-1613.

Chang, Y.-W., Huang, M.-H. and Lin, C.-W. (2015), "Evolution of research subjects in library and information science based on keywords, bibliographical coupling, and co-citation analyses", Scientometrics, Vol. 105 No. 3, pp. 20171-2087.

Chu, H. (2015), "Research methods in library and information science: a content analysis", Library and Information Science Research, Vol. 37 No. 1, pp. 36-41.

Deng, S. and Xia, S. (2020), "Mapping the interdisciplinarity in information behavior research", Scientometrics, Vol. 124 No. 1, pp. 489-513.

Figuerola, C., Marco, F. and Pinto, M. (2017), "Mapping the evolution of Library and information science using topic modeling on LISA", Scientometrics, Vol. 112 No. 12, pp. 1507-1535.

Han, X. (2020), "Evolution of research topics in LIS between 1996 and 2019: an analysis based on Dirichlet allocation topical model", Scientometrics, Vol. 125, pp. 2561-2595.

Hider, P. and Pymm, B. (2008), "Empirical research methods reported in high-profile LIS journal literature", Library and Information Science Research, Vol. 30, pp. 108-114.

Hou, J., Yang, X. and Chen, C. (2018), "Emerging trends and new developments in information science: a document co-citation analysis (2009-2016)", Scientometrics, Vol. 115 No. 1, pp. 869-892.

Hsiao, T.-M. and Chen, K.-H. (2020), "The dynamics of research subfields for library and information science: an investigation based on word bibliographic coupling", Scientometrics, Vol. 125 No. 1, pp. 717-737.

Huang, M.-H., Shaw, W.-C. and Lin, C.-S. (2019), "One category, two communities: subfield differences in "information science and library science" in journal citation reports", Scientometrics, Vol. 119 No. 2, pp. 1059-1079.

Järvelin, K. and Vakkari, P. (1990), "Content analysis of research articles in library and information science", Library and Information Science Research, Vol. 12, pp. 395-421.

Järvelin, K. and Vakkari, P. (1993), "The evolution of library and information science 1965-85: a content analysis of journal articles", Information Processing and Management, Vol. 29 No. 1, pp. 129-144.

Li, P., Yang, G. and Wang, C. (2019), "Visual topical analysis of library and information science", Scientometrics, Vol. 121 No. 3, pp. 1753-1791.

Liu, P., Wu, Q., Mu, X., Yu, K. and Guo, Y. (2015), "Detecting the intellectual structure of library and information science based on formal concept analysis", Scientometrics, Vol. 104 No. 3, pp. 737-762.

Ma, J. and Lund, B. (2020), "The evolution of LIS research topics and methods from 2006 to 2018: a content analysis", Proceeding 83rd Annual Meeting of ASIS\&T 2020, Vol. 57, p. e241, doi: 10. 1002/pra2.241.

Milojevic', S., Sugimoto, C.R., Yan, E. and Ding, Y. (2011), "The cognitive structure of library and information science: analysis of article title words", Journal of the Association for Information Science and Technology, Vol. 62 No. 10, pp. 1933-1953.

Miyata, Y., Ishita, E., Yang, F., Yamamoto, M., Iwase, A. and Kurata, K. (2020), "Knowledge structure transition in library and information science: topic modeling and visualization”, Scientometrics, Vol. 125 No. 1, pp. 665-687.

Onyancha, O. (2016), "Forty-five years of LIS research evolution 1971-2015: an informetrics study of the author-supplied keywords", Publishing Research Quarterly, Vol. 34, pp. 456-470.

Peritz, B.C. (1980), "The methods of library science research: some results from a bibliometric survey", Library Research, Vol. 2 No. 3, pp. 251-268.

Sugimoto, C. (2011), "Looking across communicative genres: a call for inclusive indicators of interdisciplinarity”, Scientometrics, Vol. 86, pp. 449-461.

Tuomaala, O., Järvelin, K. and Vakkari, P. (2014), "Evolution of library and information science, 19652005: content analysis of journal articles", Journal of the Association for Information Science and Technology, Vol. 65 No. 7, pp. 1446-1462. 
Ullah, A. and Ameen, K. (2018), "Account of methodologies and methods applied in LIS research: a systematic review", Library and Information Science Research, Vol. 40 No. 1, pp. 53-60.

Vakkari, P. (1994), "Library and information science: its content and scope", in Godden, I.P. (Ed.), Advances in Librarianship, Academic Press, San Diego, CA, Vol. 18, pp. 1-55.

Whitley, R. (1984), The Intellectual and Social Organization of the Sciences, Clarendon Press, Oxford.

\author{
(1)
}

\title{
Appendix 1
}

\begin{tabular}{|c|c|c|c|}
\hline Journal name 2015 & Vols & No of arts & \\
\hline ACM transactions on information systems & $33(1)-34(1)$ & 27 & \\
\hline Aslib journal of information management (formerly: Aslib Proc.) & 67 & 36 & \\
\hline College and research libraries & 76 & 57 & \\
\hline Information and culture (formerly: Libraries and culture) & 50 & 24 & \\
\hline Information Processing and management & 51 & 65 & \\
\hline Information research & 20 & 46 & \\
\hline Information retrieval & 18 & 21 & \\
\hline Information services and use & 35 & 27 & \\
\hline Information technology and libraries & 34 & 19 & \\
\hline International information and library review & 47 & 10 & \\
\hline International journal of information management & 35 & 71 & \\
\hline Journal of documentation & 71 & 64 & \\
\hline Journal of education for library and information science & 56 & 23 & \\
\hline Journal of information science & 41 & 57 & \\
\hline Journal of librarianship and information science & 47 & 28 & \\
\hline Journal of library administration & 55 & 22 & \\
\hline Journal of the association for information science and tech & 66 & 185 & \\
\hline Library and information history (formerly: Library history) & 31 & 11 & \\
\hline Library and information science research & 37 & 40 & \\
\hline Library collections, acquisitions and technical services & 39 & 11 & \\
\hline Library quarterly & 85 & 24 & \\
\hline Library resources and technical services & 59 & 15 & \\
\hline Library trends & 63 & 47 & \\
\hline Libri & 65 & 24 & \\
\hline New review of information networking & 20 & 27 & \\
\hline Online information review & 39 & 52 & \\
\hline Program & 49 & 24 & \\
\hline Reference and user services quarterly (formerly: Reference quart.) & $54(3)-55(2)$ & 12 & \\
\hline Scientometrics & $102-105$ & 345 & \\
\hline The electronic library & 33 & 70 & Table A1. \\
\hline The indexer & 33 & 30 & List of journals in the \\
\hline TOTAL & & 1,514 & data set \\
\hline
\end{tabular}


JD

78,7

86

\section{Appendix 2: The classification scheme}

Only numeric codes in italics were used in coding.

\section{LIS TOPIC - A}

010-030 Research on LIS context 010-the professions (of librarians, intermediaries) 020-library history, history of L\&I institutions 030-publishing (analyses of, incl. history)

100-300 Research on LIS studies 100-study on education in LIS Studies (studies on LIS itself, see 300) 200-methodology (study of research methods; for work task performance, see 400 . . 600) 300-analysis of LIS discipline (also LIS subareas)

400 Research on LIS service activities 410-study on document delivery (incl. circulat-ion, interlibrary loans of docs in any forms) 420-collections study (of any media, e.g. ebooks)

430-study on information or reference service

440 -study on user education or information literacy education (incl. info skills) 450-study on L\&I service buildings and facilities 460 -study on administration or planning (incl. L\&I service visions and policies) 470 -study on automation or digital libraries (if no L\&I service context, consider 540) 480 -study on other L\&I services (incl. school libraries; library's public) 490-study on several interconnected activities

500 Research in information storage and retrieval 510 -study on metadata/cataloguing (metadata for any type of docs)

520 -study on classification and indexing (content of any media objects; using any intellectual and automatic means)

530 study on information search and retrieval (clustering, filtering, recommendation, query formulation, retrieval models, QA, searching, summarization - in live or test collections, without user participation)

531-study on text retrieval methods (in live or test collections; incl. CLIR)

532-study on retrieval methods in other media (image, video, music, ..., multi and hypermedia; if focus on WWW, then 533)

533 -study on web retrieval methods

534 -study on social media retrieval methods

540 -study on digital information resources (e.g. various types of databases (incl. data journals; repositories - focus on general props and use)

550 -study on interactive (user-oriented) IR

560-study on other aspects of IR (incl., QA, archival IR system design; spoken queries)

600 Research on information seeking

610-study on information dissemination (professional, work and everyday life contexts)

620 -study on the use or users of channels or sources of information (focus on channels or sources; manual or digital)

630-study on the use of L\&I services (no other channels considered)

640 study on Information seeking behavior (focus on persons)

641 -study on task-based information seeking (tasks or interests as points of departure; incl. everyday-life tasks and info practices)

642-other type of information seeking study (ex: presence in social media sites; serendipity) 650 -study on information use (whether and how) 660 -study on information management (incl. IRM, knowledge management and sharing) 
700 Research on scientific and professional comm 710-study on scientific/professional publishing (incl. reviewing) 720-study on citation patterns and structures 730-study on web-metrics (incl. alt-metrics) 740 -study on other aspects of scientific or professional communication 800 -study on other aspects of LIS (e.g. task analysis, overview of library scene) 900-study in another discipline on LIS forum (may be relevant but focus is outside LIS)

\section{SCHOLARLINESS - $\mathbf{R}$}

0 -not research

1-research

\section{VIEWPOINT ON DISSEMINATION - P}

10-study on several interconnected phases of dissemination

11 -information producer's viewpoint

12-information seller's (marketer's) viewpoint

13-intermediary's viewpoint

14-intermediary organization's viewpoint

15-end-user's viewpoint

16-end-user organization's viewpoint

17-viewpoint of the developer of the process or a service

18-LIS educator's viewpoint

19-other viewpoint

o0-no viewpoint on information dissemination

\section{SOCIAL LEVEL - S}

1 -individual

2-organizational

3-societal

4-multi-level

0 -not applicable

\section{RESEARCH STRATEGY - M}

10 empirical research strategy

11-historical strategy

12-survey strategy (typically quant analysis, but may include qual studies)

13-qualitative strategy (prefer $M=14-16$ )

14-evaluation strategy

15-case or action research strategy (incl. critical incident)

16-content or protocol analysis (both qual and quant; incl. discourse analysis)

17-citation analysis

18-other bibliometric strategy (incl. co-authorship anal)

21-secondary analysis

22-experiment (incl. field experiment)

29-other empirical method (catch-all for any other qual or quant strategy)

30 conceptual research strategy (non-empirical)

31-verbal argumentation, criticism

32-concept analysis (incl. terminology analysis)

40-90 strategies for other non-empirical studies

40-mathematical or logical strategy (focus in formal definition)

50 -system and software analysis and design (constructive)

60 -literature review (research if analytical) 
$\mathrm{JD}$

78,7

80-bibliographic strategy

90-other strategy (incl. devel. of a method)

O0-not applicable, no strategy

\section{DATA COLLECTION METHOD - C}

10-questionnaire, interview (incl. structured and semi-structured)

15-harvesting databases or their log files (incl. social media sites)

20-observation (incl. eye-tracking, screen capture, wearable recorders)

30-thinking aloud

40-text/item collection for content analysis

50-citation data collection (e.g. co-authorship and co-citation data, altmetric data)

60-historical source analysis

70-several methods of collecting

80 -use of data collected earlier

85-IR experiment

90-other method of collecting (diary; crowdsourcing; other test)

OO-not applicable (if study is not empirical)

\section{TYPE OF ANALYSIS - Q}

1-qualitative

2-quantitative

3-mixed types

0 -not applicable (not empirical, not scholarly)

\section{TYPE OF INVESTIGATION - I}

10 empirical

11-descriptive (incl. historical)

12-comparative

13 explanatory (building/testing theory)

20-50 non-empirical contribution

20-conceptual (incl. terminological)

30-theoretical (without direct data collection)

40-methodological

50-system design (constructive)

90-00 for other empirical, non-empirical and no contributions 90-other type (examples: review; plan/design)

OO-not applicable, not a research article

\section{Corresponding author}

Kalervo Järvelin can be contacted at: kalervo.jarvelin@tuni.fi

For instructions on how to order reprints of this article, please visit our website:

www.emeraldgrouppublishing.com/licensing/reprints.htm

Or contact us for further details: permissions@emeraldinsight.com 